\title{
Logboat Repairs in Britain and Ireland: A New Typology
}

\author{
Bob Holtzman ${ }^{1}$ (D)
}

Accepted: 19 January 2021 / Published online: 23 February 2021

(C) The Author(s) 2021

\begin{abstract}
Repairs in British and Irish archeological logboats have been recorded and described by several authors, and the wide variety of repair methods present has been noted, but otherwise, repairs have received little analytical attention. This may be a result of three factors: (1) failure to recognize the significance of repair as social action; (2) the absence of a convenient source that consolidates repair data from all countries of the Atlantic Archipelago; and (3) the inadequacy of existing typologies of logboat repairs. Because they fail to recognize the distinctiveness of certain types of repairs and to organize repair methods into logical categories consistent with the data, existing typologies are of little help in comparing archeological examples or in analyzing repair methods for spatial or temporal distributions. This paper argues that logboat repairs can be socially significant; tabulates all known repairs in British and Irish logboats; describes the situations or events that make repairs necessary; and proposes a typology of repair based on general mechanical or engineering responses to logboat damage. It also presents findings of spatial and temporal distributions of some aspects of repairs.
\end{abstract}

Keywords Typologies $\cdot$ Logboats $\cdot$ Repairs $\cdot$ Ancient watercraft $\cdot$ Repair techniques

\section{Introduction}

Archeological logboat studies are common and well developed in Britain and Ireland (the "Atlantic Archipelago"), in Northern Europe in general, and to a lesser extent worldwide. Data have been amassed (McGrail 1978; Mowat 1996; Gregory 1997; Lanting 1997; Arnold 2000; Fry 2000); morphological typologies have been developed (McGrail 1978:129-130, 2001:172-179; Gregory 1997:3-7; Arnold 2018); construction methods have been studied using archeological evidence (Millett et al. 1987:127-131; Goodburn 2010) and experimental archeology (McGrail 1978:114-116; Goodburn and Redknap 1988; Gregory 1997:172-197; Crumlin-Pedersen and Jensen 2018); and performance has been assessed on paper (McGrail 1978:131-142), in experimental reconstructions (Gregory 1997:172-197), and through digital methods (Tanner 2019). Logboats have been

Bob Holtzman

rsh1n18@soton.ac.uk

1 Centre for Maritime Archaeology, University of Southampton, Southampton SO17 1BF, Hampshire, United Kingdom 
considered as manifestations of material culture, and their influence and impact on social lives documented and theorized upon archeologically (Strachan 2010a; Markoulaki 2015) and ethnographically (Ransley 2009; Fuquen Gomez 2014; Markoulaki 2015; Blue et al. 2017).

Largely omitted from logboat studies, however, has been consideration of repair. Although repairs in archeological logboats are often recorded and described, their significance is rarely discussed other than as evidence of a boat's longevity (Christensen 1990:131; Andersen 1994:8; Strachan 2010a:168; for exceptions, see van Rensburg 2010; Fenwick 2015; Blue et al. 2017). Like "making," however, repair is socially significant, indicative not only of techniques and access to materials (Graham and Thrift 2007:4-6; Kyle 2012:86), but also of the meaning of the repaired object to its owner or society (Caple 2006:189; Jervis and Kyle 2012:3; Kyle 2012:86; Wheeler 2012:97; Hsieh 2016:281-283). Patterns of repair can be indicative of owners' ontologies of things and how they work (or don't) (Graham and Thrift 2007:2-3, 5, 8, passim; Gregson et al. 2009:250; Houston 2017:55).

Willmott is among the few archeologists who have paid attention to repairs as theoretically significant. "Even if solely for the function of prolonging the period of use, this intentional act [of repair] is very telling about the role of the artefact and the relationship it had with its users," he writes (2001:103), continuing:

The presence of repair, whatever the reasons for it, has serious implications for the way the use of material culture is viewed in past societies. It is an area that cannot be ignored. Indeed it has the potential to be a meaningful tool in the understanding of the relationships between material culture and its users in the past (Willmott 2001:104).

Among the first steps toward the serious consideration of logboats as archeologically significant objects were the comparison of design and construction features and the creation of simple morphological typologies that allowed for easy description and comparison of different examples. This paper attempts to take comparable steps toward a serious consideration of logboat repairs, assembling or consolidating the archeological data from Britain and Ireland and organizing that data into typological categories for ease of comparison and analysis.

First, it is necessary to describe the situations that make repairs necessary, because different situations and types of damage may require different repair responses. For this, we draw data from archeological and ethnographic examples worldwide.

\section{Occasions for Repairs}

Repairs occur for a variety of reasons and at various stages during a logboat's existence. These repair "occasions" are described below.

\section{Maintenance Versus Repair}

For the purposes of this study, a repair is defined as an observable feature made to correct existing damage or wear. This specifically excludes actions, construction features, and wood treatments or coatings meant to prevent or minimize later damage or wear. For example, the annual cleaning and oiling performed by logboat owners in Kerala, India (Ransley 
Fig. 1 A cleat nailed into the end grain to secure a split at the stern of a logboat under construction, Napo Province, Ecuador. According to the boat's owner and builder, the log split when the tree was felled. (B. Holtzman)

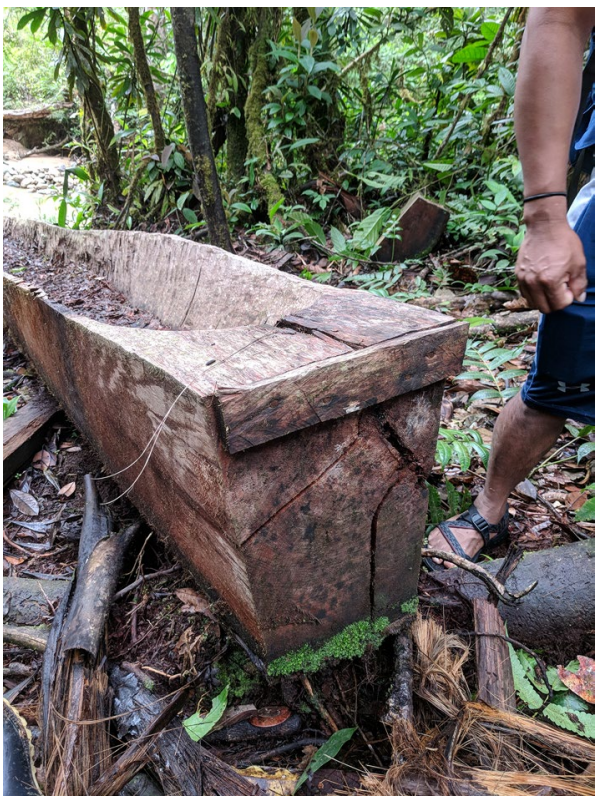

2009:132), constitutes maintenance: it protects the boat from future damage from marine borers and excessive drying but does nothing to correct existing damage.

Repair and maintenance may overlap, however, in definition and in practice. A hypothetical scenario will suffice to illustrate the occasional difficulty distinguishing between them. A boat owner is scraping the bottom of a boat as part of its annual cleaning (i.e., maintenance) and finds that a section of the hull has been damaged by marine borers, leaving some tiny holes in the wood. If the bad wood is cut out, and new wood scarfed in, a repair is clearly being performed. But if, instead, the tiny holes are filled with a material such as tar, has the owner simply continued the maintenance process, or was this a repair? The damage is the same and the end effects of the alternative procedures are comparable. But applying a dab of filler is similar to, and scarcely interrupts, the other work of maintenance, while the scarf repair, in contrast, would require finishing or setting aside the cleaning process, gathering different tools and materials, and engaging in distinctly different techniques. Although I seem to be making a case for maintenance, I would argue that this is a better characterized as a (minor) repair of the "soft filler" category, to be described below. The typology proposed, however, is not meant to be a straightjacket into which every repair must be confined; rather, it is intended as a tool to easily describe and compare repairs, including those that do not precisely fit the category definitions.

\section{Construction Events}

Repairs are often required while a logboat is under construction (Ransley 2009:117). Regardless of the care with which a tree is chosen, a trunk might contain flaws that become apparent only after construction begins (Goodburn 2019:20-21), and flawed trees might be chosen knowingly due to scarcity of better ones (Goodburn 2010:100). An otherwise sound tree can be damaged when it is felled or might split during construction due to internal stresses in the $\log$ (pers obs) (Fig. 1). Likewise, errors by the builder might require repairs 
to correct (Millett et al. 1987:120). The builder's willingness to perform repairs during construction is surely related to the amount of labor invested prior to the flaw's appearance (e.g., two man-days of labor to fell an oak $1.1 \mathrm{~m}$ in diameter using bronze axes, per Darrah 2004:181), and to the scarcity and value of appropriate trees, especially in the case of large boats (Goodburn 2010:100; 2019:20).

From late Saxon times onward, if not earlier, top-quality (long, straight, knot-free) oak trunks were largely reserved for other purposes (such as the production of planks for planked boat and ship building), and logboat construction perforce relied upon second-quality timber with more knots and other defects (Goodburn, Damian: pers comm 05/01/21). This could have necessitated more repairs during construction and, later, during the boat's period of use.

\section{Preventive Repairs}

Almost all known British and Irish logboats are built of oak, ${ }^{1}$ which is prone to splitting (Boulton and Jay 1944:55). Transverse members-including fitted ribs, and cleats or plates of wood mounted on top of a boat's ends-may be fitted to prevent splitting (McGrail 1978:318-319; Gregory 1997:107) or to repair an existing split (e.g., the Banks boat; McGrail 1978:153). (Henceforth, bold type within citation brackets indicate boat names.) Where logboats are discovered with no split beneath such fittings, they are what Gregory terms a "preventive repair" (1997:107). In many cases where splits appear beneath such fittings, it is unclear whether these are post-damage repairs or preventive repairs that ultimately failed to prevent the split (which is not to say that it might not have successfully postponed it for a very long time). So-called preventive repairs cannot be considered true repairs, as they do not correct damage, but rather strengthen the boat and extend its working life. In place of Gregory's "preventive repair," therefore, the terms "strengthening fitting" (per McGrail 1978:318-319) or "reinforcement" are more appropriate.

\section{In-Use Damage}

During a wooden boat's working life, damage that impairs its functionality or prevents its use altogether may be caused by both discrete incidents and chronic conditions. The primary types and causes of in-use damage are listed in Table 1.

As discussed, some repairs to in-use damage are difficult to distinguish from reinforcements. Almost any fitted component installed during construction might be replaced due to later damage. If holes associated with the original fasteners are reused in the replacement, then it might not be distinguishable from original construction. If the original holes are not reused and remain visible, this might be evidence of a repair.

\section{Refitting}

A refit is the replacement of a large proportion of a vessel's fittings, which may be necessary when they are damaged or worn out, or to modify or upgrade the vessel's capabilities.

\footnotetext{
${ }^{1}$ Analysis of 313 logboats with identified wood type in England and Wales (McGrail 1978:309), Scotland (Gregory 1997:162), and Ireland (Gregory 1997:162; Lanting 1997:628/table 1) shows that 96.5\% were oak.
} 


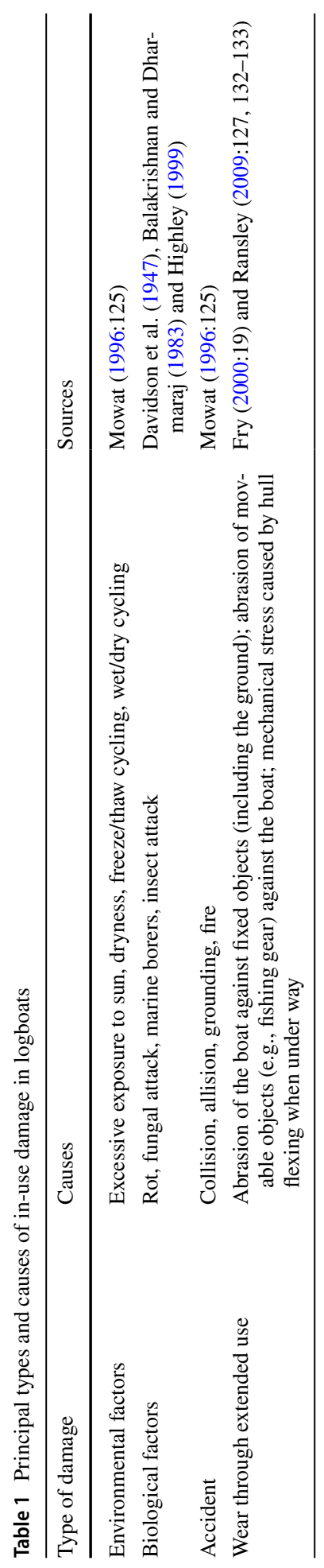




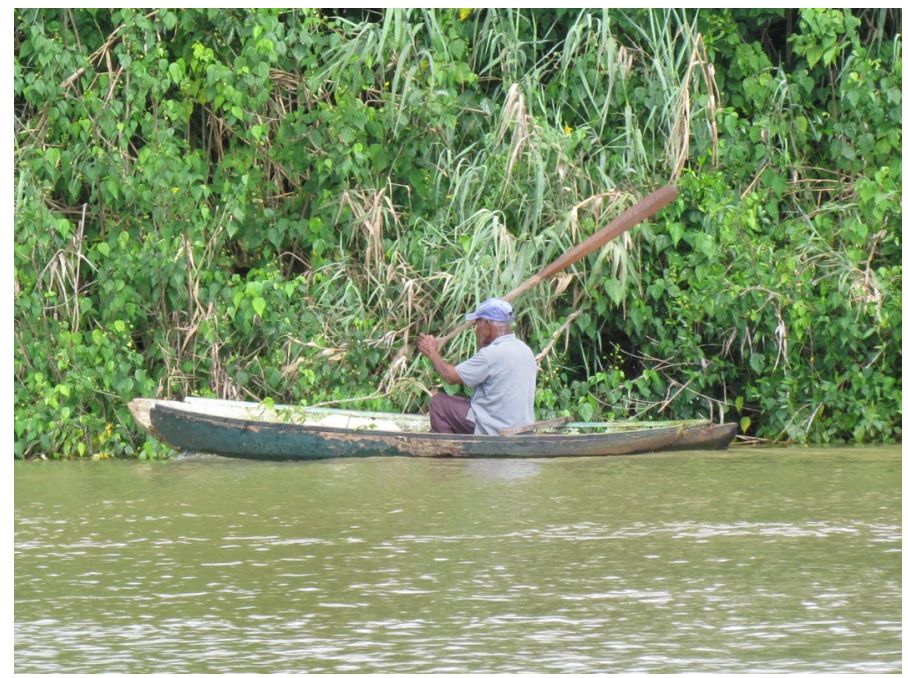

Fig. 2 A split at the bow above the waterline on this logboat significantly reduces the boat's freeboard forward but does not prevent its use. Toledo District, Belize. (B. Holtzman)

Refitting is possible only on vessels with a large number of discrete components or systems that can be removed and repaired or replaced. "Basic" (i.e., one-piece) logboats are therefore not subject to refit, while moderately complex logboats (i.e., those with added components such as a fitted transom and washstrakes) are.

Prior to the annual round of Kula voyages in the Massim region of New Guinea, all canoes intended for voyaging were completely disassembled and then reassembled using the same procedures as in new construction (Malinowski 1922:124, 377). Malinowski did not describe repairs in any detail separate from his description of new building and did not report how frequently components were replaced as opposed to being removed and reattached with new stitches or lashings. Within the context of refitting, the replacement of old components with new ones might properly be termed "repairs," while the removal and reinstallation of existing components (i.e., the renewal of lashings) is a form of maintenance.

\section{Unrepaired Damage}

Wear or damage does not always spur a repair response. The "do not repair" option suggests at least four alternative courses of action.

\section{Continue to Use "as is"}

Not all damage require repair, and some might be postponed for a long time before they become necessary. When ships remain in use in spite of being badly damaged, the owner can either consciously accept an elevated level of risk (Adams 2013:17-18) or restrict the boat to less demanding uses in order to maintain a reasonable safety margin. See Fig. 2 for a probable example of the latter.

Other forms of damage do not affect safety. For example, in Kerala, some fishing logboats have integral ribs which do not do much (if anything) to strengthen the hull, but 


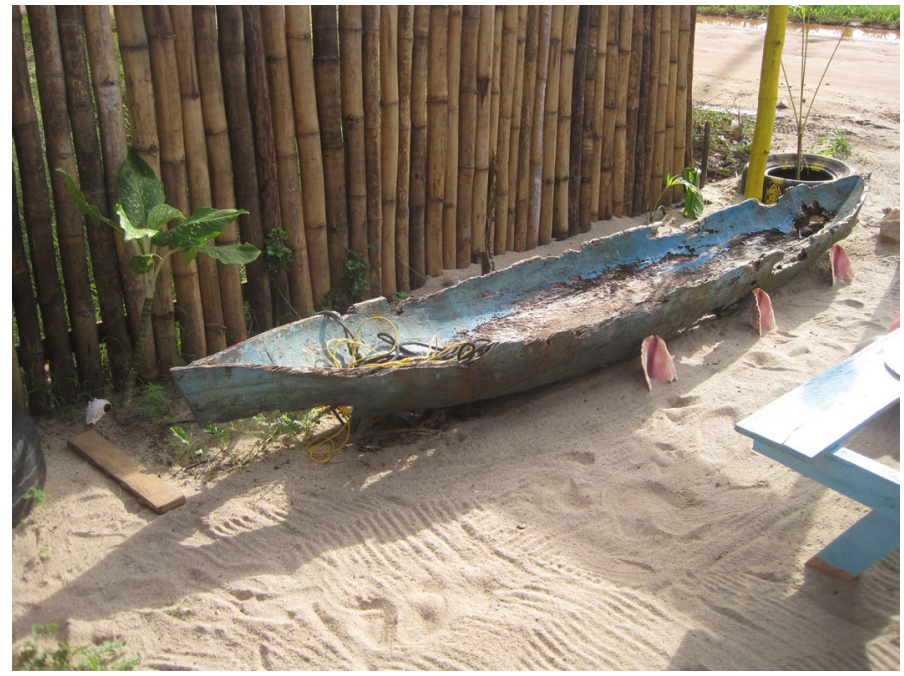

Fig. 3 A logboat beyond repair used as décor in the outdoor seating area of a restaurant in Hopkins, Belize. (B. Holtzman)

they allow the fisherman to maintain separate wet and dry areas in the interior. If the ribs become worn down over time, the owner might not perform a repair, choosing to accept having no "dry" compartment as a minor reduction of functionality with no implications for the boat's safety. Even if the damage is of a progressive type that will ultimately render the vessel unusable, it might be accepted for a long time without serious safety implications, with the intention of replacing the boat when necessary (Ransley 2009:136).

\section{Abandonment, Destruction, Salvage}

Every boat eventually reaches a stage at which damage is so extensive that further repairs are impractical (Adams 2013:19). At this stage, the boat might be simply abandoned where it lies, moved to some out-of-the-way location and allowed to rot, or burned (ibid). Alternately, it may be disassembled or broken up, its components and materials being salvaged and reused in other watercraft or other applications altogether (Edberg 2013:197-199).

\section{Repurpose}

Logboats beyond repair that remain more or less intact are occasionally employed in other applications. These include use as garden planters (Fuquen Gomez 2014:194-198), seats, washtubs, vessels for food preparation, brewing vats (Yde 1965:36; Gilmore et al. 2002:12), and décor (pers obs) (Fig. 3).

\section{Ritual Deposition}

Boats often appear in the archeological record in ritual depositions (Adams 2013:19). Logboats were ritually deposited in a variety of conditions, suggesting a variety of meanings. Some appear to have been deposited in good, or even brand new, condition (e.g., Fiskerton; Markoulaki 2015:21-22). Others were older and had obviously seen use (e.g., 
Table 2 Repaired logboats by region

\begin{tabular}{lllll}
\hline Region & Total logboats & $\begin{array}{l}\text { Logboats with } \\
\text { repairs }\end{array}$ & $\begin{array}{l}\text { Percentage of boats } \\
\text { with repairs }\end{array}$ & Sources \\
\hline England and Wales & 179 & 16 & 8.9 & McGrail (1978) \\
Scotland & 71 & 11 & 15.5 & Mowat (1996) \\
Ireland & 404 & 31 & 7.7 & Gregory (1997) \\
Totals & 654 & 58 & 8.9 & \\
\hline
\end{tabular}

Must Farm 1 and 2; Robinson et al. 2012:252-253). Some were deposited with repairs intact (e.g., Brigg; McGrail 1978:166), while others had their repairs broken or dismantled before deposition (Markoulaki 2015:208-209). It is clear that boats did not need to be pristine in all ritual depositions, and it is possible that boats at or near the end of their useful lives were selected sometimes as the most economical choice when a boat offering was required. The intentional dismantling of some boats or repairs might be a ritual "killing" (Markoulaki 2015:216-217) in the same manner that pottery in funerary contexts is sometimes intentionally broken (e.g., Budka 2010:29, 54-55, 61), or might have been intended to discourage the boats' reuse outside the ritual context (Adams 2013:19).

\section{Replace}

The owner of a damaged logboat who still requires a boat has two options: repair or replace. Repair was probably the more economical and practical option by far in many situations (Holtzman 2019:56-60). But a desire for the new, or a distaste for the visibly used, might overrule practical considerations, tipping the decision toward the replace option (Gregson et al. 2009), especially if the boat is used for status display.

\section{Frequency of Repair}

Repairs are common among British and Irish logboats, appearing in roughly $9 \%$ of reported finds (Table 2). There are reasons to believe that logboats were repaired more frequently than this figure suggests. Many reports of logboat finds inventoried by McGrail (1978), Mowat (1996) and Gregory (1997)—especially those made before the development of modern archeological practices-lack even the most basic information. In such cases, it is likely that any repairs present were not recorded and, unfortunately, many of these older finds are lost forever, precluding reexamination. Even among well-recorded logboat finds, few are recovered complete. The bottom of the hull, which is frequently all that remains, is not only the thickest part of the boat (McGrail 1978:33), but also the least subject to drying out during its period of use (Goodburn 2019:31). Both of these factors could make the bottom the part least likely to be damaged (and therefore, repaired). In contrast, the boat's sides, being thinner and more subject to drying out, are more likely to be damaged in use and less likely to be recovered archeologically.

The author's personal observation in an ethnographic context supports this conclusion. An examination of 24 logboats photographed during unpublished fieldwork in Ecuador's Rio Napo drainage in 2018 reveals repairs in at least 19 (79.2\%) of them. That none of these were built of British oak species is just one of many factors making direct analogies 
between such widely different times and locales risky (Gould 1980:29-36; Wylie 1985; David and Kramer 2001:33-54), but the observation nonetheless supports the commonsense notion that logboat owners-like boat owners everywhere-will typically repair damage whenever possible, in preference to building a new boat as a replacement.

\section{Who Performs Repairs?}

It has been documented ethnographically that logboat repairs may be performed by both experts and non-specialists within a single community (Ransley 2009:132-133; Fuquen Gomez 2014:166, 167/fig.6.60, 169, 169/fig.6.63, 170/fig. 6.64), the deciding factor appearing to be the complexity of the repair. A similar distinction is thought to have applied to the construction of archeological logboats, with larger and more complex boats being managed by specialists (McGrail 1978:35; Millett et al. 1987:131; Goodburn 2010:113; Strachan 2010a:171), and smaller, simpler ones being built by their owners, at least occasionally (Marsden et al. 1989:102-103; Strachan 2010a:171). It is reasonable to conclude, therefore, that complex repairs in archeological boats, like the Hasholme logboat's carefully rabbeted portside hull insert and the repair block inserted beneath its transom (Millett et al. 1987:119-120), were the work of experts, while simple ones, like the nailed patch in the Wasdale Beck boat (Cherry and Cherry 1984:105, 109/Pl.4), could have been performed by owners who were not boatbuilding specialists.

The social role or "professional" status of the individual doing a repair may influence his access to tools and materials, and therefore the technique used, just as it may apply in logboat construction (Marsden et al. 1989:102-103). Damian Goodburn has suggested that "a small peasant farmer may not have the wider tool kit of a medieval abbey for example" (pers comm, 05/01/21). Any peasant would probably have access to a hammer, which could manifest itself in nailed repairs, while a well-funded woodworking specialist might own a variety of chisels, gouges, planes, and augers, which would make rabbeted joints and treenail fastenings (i.e., large-diameter wooden pegs) practical.

Ethnography shows that logboat owners often perform repairs ad hoc, making use of any material and technique that might return the boat to service expeditiously. In Kerala, India, when integral frames which serve to separate "wet" and "dry" areas within the logboat are worn down by abrasion, owners sometimes build them up with mud, although at other times they nail in a piece of timber (Ransley 2009:126, 132). [In contrast, when these boats are repaired by Kerala professionals, the integral frames are painstakingly recreated, but when they are repaired by professionals from a different building tradition, the frames may be omitted altogether, even though the repair is made in a "shipshape" manner (Blue et al. 2017:190-191).] Other expedient repairs observed in ethnographic contexts include patches made from a discarded flip-flop in Tanzania (Blue, Lucy: pers comm, 7/9/19) and from sections of plastic bulk food containers (probably high density polyethylene) in Ecuador (pers obs) (Fig. 4).

Therefore, as with the method of repair chosen, the choice and treatment of repair materials can be indicative of aspects of the boat's history, such as the status or role of the craftsperson, the locale, and the repair's approximate date. Among British and Irish logboat repairs, wood patches, cleats, plates, and repair frames are of oak in nearly all reported instances. Details of the method of manufacture, as indicated by tool marks or wood grain orientation, are rarely reported, but when present can be valuable aids to interpretation (e.g., Strachan 2010b:77-80). 


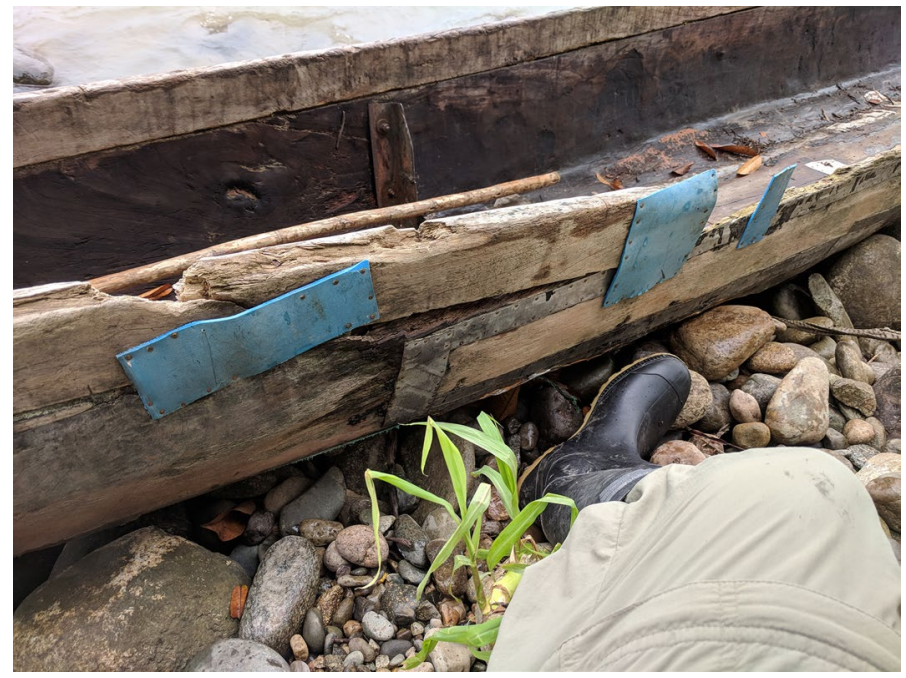

Fig. 4 Patches cut from plastic food barrels on an extended logboat, Rio Napo, Ecuador. (B. Holtzman)

\section{Previous Typologies}

Previous attempts to create a typology of logboat repair methods have been inadequate. Using worldwide archeological and ethnographic data, McGrail organized all repairs into two categories: "those pulling a split together; and those where a patch or tingle is fitted over a more serious split or hole" (1978:37, emphasis added). As an example of the first type of repair, McGrail cites "tar used to seal splits" (ibid). Although tar might shrink a small amount upon drying, it doubtful that this shrinkage could do much to pull a split together, and its main purpose is simply to fill the gap in the wood. This method therefore represents a third type of repair. ${ }^{2}$ A fourth type of repair present in examples in McGrail's inventory but not considered in his typology is that of "graving pieces"-i.e., pieces of new wood scarfed flush into the hull to replace rotten or broken sections (e.g., Brigg, Holme Pierrepont 3; McGrail 1978:166, 210 respectively). Finally, "pulling" and patching repairs are not reliably distinguished by the latter being applied to "more serious" splits or holes. Some very serious splits are repaired with pulling techniques (e.g., Appleby; McGrail 1978:147) and some examples of minor damage are repaired with patches (e.g., Banks; McGrail 1978:153).

In his analysis of Scottish logboats, Mowat notes that "many 'repairs' may have been carried out during construction to remedy defects in the available timber" (1996:125-126). Like McGrail, he recognizes two main types of repair:

\footnotetext{
2 McGrail later revised his description of the first main type of repair as "those sealing a split" (1998:65), citing as an example: "Tar and creepers have been used to seal or bind splits in S. American logboats" (ibid, emphasis added, internal citation omitted). In this, he correctly distinguishes between sealing and binding as different methods having different functions, but still places them in a single category characterized by the nature of the damage rather than the mechanics of the repair.
} 
It is inherent in the manufacture of logboats by a reduction technique that new components cannot be fabricated to directly replace those rendered defective, but, rather, that repair-patches or lashings must be fabricated... (Mowat 1996:126, emphasis added).

By qualifying that logboats manufactured "by a reduction technique" (i.e., solely by the removal of material from the solid tree trunk) are subject to only two types of repairs, Mowat may be tacitly acknowledging the possibility of a third category that could apply to the replacement of broken or worn fitted components in logboats built by combined reduction and addition (or construction) techniques (as defined by McGrail 1998:105-106, 109). And Mowat hints at a fourth category in a list of Scottish repairs, which he organizes under three subheadings: patches, stitching, and "block or timber inserted into hole or split" (1996:126, emphasis added). This is the same as the use of flush-set graving pieces that McGrail (1978:37) failed to distinguish as a "type" or category, as described above.

Gregory follows McGrail in acknowledging only two categories of repairs-pulling and patching (1997:107) — even though examples of gap-filling repairs (e.g., Clooncoe 1; Gregory 1997:323) and graving pieces (e.g., Mullynascarty; Gregory 1997:489) appear in his inventory of Irish boats. Gregory identifies two general occasions for repairs, which he calls both "types" and "methods": "preventive repairs" and "post-damage" (1997:107), and states that "(b)oth methods employ a pulling technique while application of a patch is used in post-damage repairs only" (ibid). He confuses the issue by stating that all identifiable Irish repairs used a pulling technique (Gregory 1997:110). Given that several repairs in the Irish inventory are patches (e.g., Clooncunny 2, Currygrane; Gregory 1997: 325, 358 respectively), this incorrectly equates patching with pulling. As will be discussed below, some patches do not perform a pulling function. Gregory's typology fails to accommodate the wide variety of repairs present in his inventory (e.g., patches, graving pieces, stitching, fasteners used by themselves), and he finds "few common features" except for the frequent use of patches in both Irish and Scottish boats (1997:109).

Fry avoids McGrail's and Gregory's dichotomization of repairs, observing that small leaks can be stopped up with "(n)aturally occurring substances" (Fry 2000:20). He states that "(s)cope for really major repairs and refitting ... remain limited " (Fry 2000:20), but shortly contradicts himself by citing examples of major repairs:

It may have been possible to insert a transom in a deteriorating stern, and to do something about tears which lay clear of the water line. And occasionally quite extensive cracks in the floor and sides were tackled, though perhaps more in hope than with any real long-term expectation of success (Fry 2000:20).

After citing an extensive nailed patch repair, he continues:

Generally, though, damage of this kind in all likelihood lay beyond effective solution, and ended in write off (Fry 2000:20).

Fry makes a number of errors here. Although fitted transoms may sometimes be installed as repairs, most appear to have been original construction features (McGrail 1998:80-82). Given the frequency with which repairs appear in the archeological record and the likelihood that they were more common than the record suggests, it is clear that steps were often taken to avoid a "write off." Most importantly, there is no reason to believe that boat owners and craftsmen of the past were less concerned with efficacy or less cognizant of effectiveness than their modern counterparts. Lacking evidence to the contrary, one must assume that repairs were made with a realistic "long-term expectation of success". 
Existing typologies, therefore, fail to recognize or accommodate several repair methods present in the archeological record, or they assign methods to inappropriate categories. A more accurate and comprehensive typology would be useful toward an understanding of the technological choices and affordances available to logboat users in various eras and locations, and might reveal patterns of temporal and spatial distribution that might be culturally significant.

\section{Methodology}

An effort was made to collect data on every known example of pre-deposition repairs in British and Irish logboats. A thorough review was performed of the four logboat inventories discussed in the previous section [McGrail's Logboats of England and Wales (1978); Mowat's The Logboats of Scotland (1996); Gregory's A Comparative Study of Irish and Scottish Logboats (1997); and Fry's Coití: Logboats from Northern Ireland (2000)]. This was followed by systematic searches in general and academic search engines and in relevant databases and journals for examples of more recently reported logboat repairs.

Data were entered into an Excel spreadsheet (appended to the electronic version of this paper as the "Data Table"). In addition to each boat's name, find location, primary dimensions, dating, and literature citations, data were recorded in five fields for each instance of repaired damage: (1) nature of the damage; (2) basic method of repair; (3) refinements to the basic method; (4) type of fasteners; (5) caulking material. Variables within each field were modified and added to as data were collected. For example, when a source described a repair that did not coincide with one of the existing "basic methods," a new method variable was defined to accommodate it. A numerical coding system was used to record the specific data for each of the five fields (see the "Repair Code" tab in the Data Table), allowing the data to be interrogated for frequency and distribution.

\section{Results}

The search of the archeological record identified 73 repaired logboats incorporating 128 repairs. Repaired boats were identified mostly in geographic clusters in Ireland, the Scottish Lowlands, and eastern and western England (Fig. 5), with dates ranging from the Middle Bronze Age to the post-medieval period, although only 29 (39.7\%) are securely dated.

A single repair was present in 39 of the 73 boats (53.4\%), while 24 boats (32.9\%) had two repairs. Lesser numbers had three, four, five, or six repairs, with none having more than six. There was no correlation between number of repairs and boat length $\left(R^{2} \sim 0.05\right)$ or between number of repairs and a rough index of boat volume (calculated as the product of length $\times$ width $\times$ height $)\left(\mathrm{R}^{2} \sim 0.09\right)$.

Repair methods were notable for their variety, with 12 different "basic" methods identified (Table 3). The mechanical or engineering approaches underlying each of the basic methods were considered for their affinities and differences, resulting in a typology of five categories summarized below and in Table 4, and described in more detail in the following sections.

1. "pulling" repairs: in which the two sides of a split are forced together and held in place by mechanical means (Fig. 6a). 


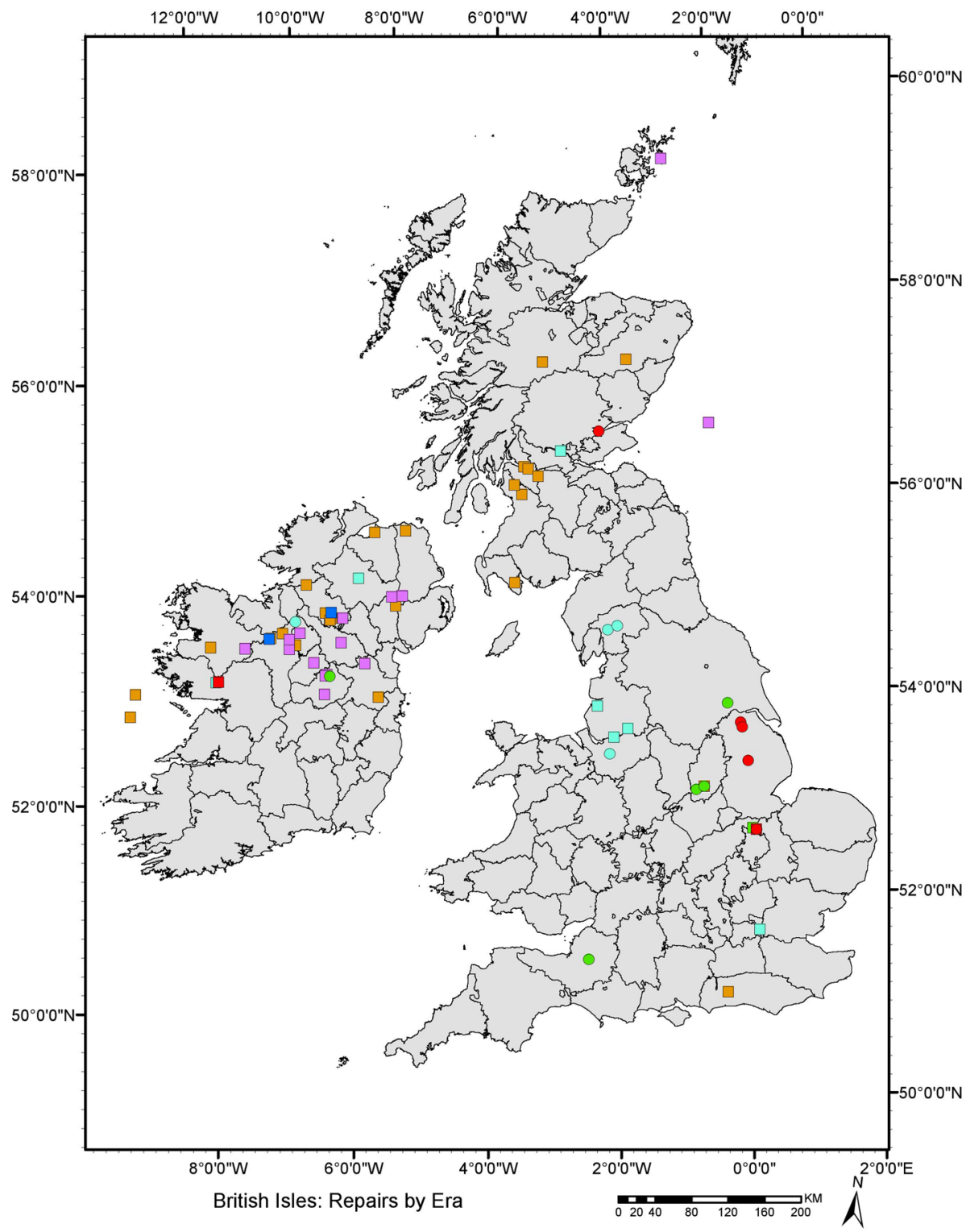

$\square$ MBA $\bullet$ LBA $\square E I A ~ O L I A ~ \square S A X ~ O M I D ~ \square P M A ~ \square I O L ~ \square n / a$

Fig. 5 Locations of repaired logboats in the British Isles, by historic period. MBA Middle Bronze Age, $L B A$ Late Bronze Age, EIA Early Iron Age, LIA Late Iron Age, SAX Anglo Saxon period, MID Middle Ages, $P M A$ post Middle Ages; IOL Iron Age or later (iron present, not otherwise dated). Three boats without provenance have been placed at arbitrary locations in the sea next to their countries of origin. (Jack Pink, used by permission) (Color figure online)

2. patches: in which damage is covered by a piece of solid material such as a board or a sheet of metal. A patch is placed over the damage and on the surface of the hull, not flush with it (Fig. 6b). 
Table 3 Frequency of logboat repairs

\begin{tabular}{lllll}
\hline Basic repair method & ${\text { \# } \text { of boats }^{\mathrm{a}}}$ & \% of boats & \# of repairs & \% of repairs \\
\hline Stitched & 5 & 5.6 & 10 & 7.8 \\
Metal strap & 1 & 1.1 & 1 & 0.8 \\
Metal patch & 5 & 5.6 & 6 & 4.7 \\
Key (clamp) & 3 & 3.3 & 3 & 2.3 \\
Cleat & 7 & 7.8 & 8 & 6.3 \\
Wooden patch & 28 & 31.1 & 49 & 38.3 \\
Wood insert & 14 & 15.6 & 20 & 15.6 \\
Fastener only & 5 & 5.6 & 5 & 3.9 \\
Soft filler & 7 & 7.8 & 9 & 7.0 \\
Tie rod & 4 & 4.4 & 4 & 3.1 \\
Frame & 1 & 1.1 & 1 & 0.8 \\
Patch, material n/a & 4 & 4.4 & 5 & 3.9 \\
Present & 4 & 4.4 & 4 & 3.1 \\
Other & 2 & 2.2 & 3 & 2.3 \\
Total & 90 & 100 & 128 & 100 \\
\hline
\end{tabular}

${ }^{a}$ This column involves intentional double-counting. Where a single boat has two different kinds of repairs (for example, a key and stitching) it is counted for both methods. Total boats with repairs $=73$

Table 4 Typology of logboat repairs

\begin{tabular}{ll}
\hline Category & Repair methods observed in British and Irish examples \\
\hline Pulling repairs & $\begin{array}{c}\text { Stitches, metal strap, key/clamp, cleat, wood patch, } \\
\text { fastener only, tie rod, frame }\end{array}$ \\
Patches & Lead patch, wood patch \\
Wood inserts & Graving piece, plug, block \\
Soft fillers & Vegetable matter, tar/pitch, clay, mud \\
Replacement of damaged fittings & Same as original installation (e.g., fitted transom) \\
\hline
\end{tabular}

3. wood inserts: in which a hole or gap is filled with a piece of new wood, cut and shaped to be flush with the hull (Fig. 6c).

4. soft fillers: in which soft material is forced or molded into the damage to fill a gap (Fig. 6d).

5. replacement of fittings: in which a damaged, attached component is removed and replaced with a sound one (Fig. 6e).

The typology accommodates all known British and Irish examples, with one exception discussed below. The categories are not exclusive: Some repairs use two or more strategies. For example, a patch may cover a split and perform a pulling function as well and may be supplemented with soft filler.

In addition to the 12 basic repair methods reflected in the typology, the archeological record includes five variations or refinements on the basic methods, eight types of fasteners or combinations of fasteners, and five types of caulking or filler. It was not necessary to incorporate these variables in the typology, but they are shown in the Data Table. 


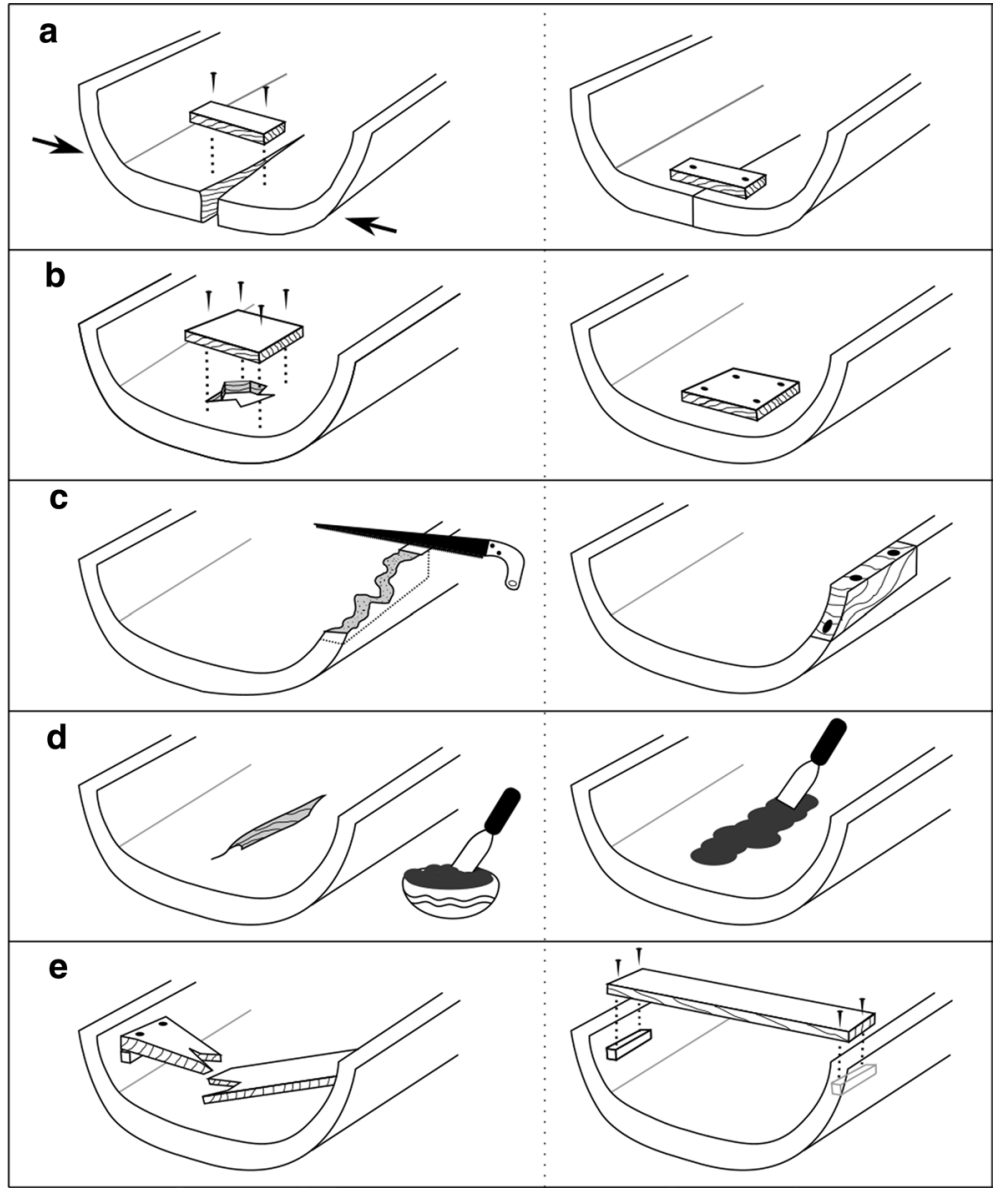

Fig. 6 Logboat repair typology. a Pulling repair. b Patch. c Wood insert. d Soft filler. e Replacement of damaged fitting. (Cate Monroe, B. Holtzman)

\section{Pulling Repairs}

Pulling repairs are applied to splits or cracks, drawing the wood together to close the gap. "Pulling" is something of a misnomer, as some pulling methods do little or nothing to actually pull the opposite sides of a split together, but only keep it from widening further. Only stitches and staples are capable of drawing a split together. In many cases, an external means of pulling or pushing (such as a Spanish windlass) might be applied to draw the split closer before it is secured by any of the methods described below. In all cases, however, the repair device is in tension once installed. 


\section{Stitches}

This pulling repair involves boring holes through the hull on both sides of the split, passing flexible cordage (or its equivalent, such as withies) through the holes, and tying it tightly (e.g., Loch Laggan 2; Mowat 1996:62). In one instance (Claggarnagh; Gregory 1997:318), the stitches do not pass through holes, but rather, wrap around pegs driven part way into the inside surface of the hull on both sides of the split.

Where stitch repairs are made below or near the waterline, the holes must be plugged to exclude water. This may be done with wooden plugs, a method that appears only in the Appleby boat (Dudley 1943:158-161; McGrail 1978:147). Holes can also be plugged with soft, moldable material such as clay, tar, or a mixture of wax and resin (Marsden 2004:40), but no instances of this method appear in the data. Since some means of stopping the holes are essential, either or both methods must have been more common than the data currently indicate.

Some splits were caulked with soft material such as moss or other vegetable matter before being pulled together (e.g., Lee's Island; Brady 2014:37). As with the use of soft material for plugging stitch holes, the practice might have been more common than the evidence suggests.

Another refinement found in some stitched repairs is the placement of a batten over the split and beneath the stitches on the inside of the hull (e.g., Loch Laggan 2; Mowat 1996:62). The batten probably served to hold wadding in place over the split.

\section{Other Pulling Techniques}

Several other techniques are seen in pulling repairs. A cleat is a short section of timber placed across a split, often on the upper surface of a boat's end, and fastened with nails or treenails (e.g., Glassaneeran Upper 2; Gregory 1997:427). A beam tie or tie rod is a longer piece of timber, usually extending between opposite gunwales. Most beam ties appear to be associated with fitted transoms in new construction as a means of preventing the gunwales from spreading (e.g., Holme Pierrepont 3; McGrail 1978:210), but some were repairs. In the Short Ferry boat (McGrail 1978:271), a length of timber with a dovetail cross section was let into a dovetail-shaped groove across the exterior of the boat's bottom to secure a split.

Fitted frames, fastened to the hull with nails or treenails, may be used as strengthening features or to facilitate the addition of washstrakes in original construction (e.g., Derryinver; Fry 2000:67) or as pulling repairs (e.g., Kilturbid; Gregory 1997:446). Nails, treenails, or iron staples may also be used by themselves to hold a split together (e.g., Glastonbury; McGrail 1978:195). Wood patches, while serving primarily to cover damage (see below), may also serve a pulling function similar to cleats.

A final pulling repair method involves cutting matching recesses into the inner surface of the hull on opposite sides of a split, and fitting a wooden "key" or "clamp" into them to lock the sides together. This kind of repair is called a "double dovetail clamp" by McGrail (1978:37) and a "dovetail joint" by some others (e.g., Creasman 2010:116 passim), but the term is problematic, as not all clamps that operate on this principle are dovetail shaped. Dudley describes the H-shaped clamps in the Appleby boat as "double-headed cleats ... recessed into the timber" (Dudley 1943:161). Neither "clamp" nor "cleat" is really satisfactory, as the former, by itself, is ambiguous and subject to misinterpretation, and the latter 
implies surface mounting. Of the two terms in use in the literature, "key" might be preferable overall.

\section{Patches}

A patch (also known as a tingle) can be placed over almost any kind of hull damage, including splits, holes, and rot. Patches in the data were either wood (e.g., Mill Lough Killyfole; Fry 2000:83) or sheet lead (e.g., Kentmere 1; McGrail 1978:223). Wood patches were secured with treenails or metal (iron) nails. Lead patches were secured with metal nails.

Most patches, especially those placed below the waterline, are on the inside of the hull, as placement on the outside would make them vulnerable to damage and create drag that would impair the boat's performance. In one instance, a hole was covered with two patches, one inside and one outside the hull (Holme Pierrepont 2; McGrail 1978:207). Caulking or wadding can be placed beneath a patch to improve its water tightness. As mentioned above, the use of caulking with patches may have been more common than is suggested by the data.

In addition to simply covering flaws, wood patches can be installed in tension over a split and so also serve a pulling function, although this is often not possible to establish from the artifact (McGrail 1978:37). Sheet lead is probably too soft to serve a pulling function as it would tear out around the nails.

\section{Wood Inserts}

Various kinds of hull damage can be repaired by cutting it out as far as undamaged wood and inserting a new, carefully shaped piece of wood in its place that sits flush with the hull. Knot holes can also be filled in this manner. The repair piece can be in the form of a plug (e.g., Brigg; McGrail 1978:166), a block (e.g., Hasholme; Millett et al. 1987), or a plank (e.g., Holme Pierrepont 2; McGrail 1978:207), in which case it may be termed a "graving piece." Nails or pegs may be used to secure the replacement piece, and repairs are sometimes supplemented with soft filler to seal remaining gaps.

\section{Soft Filler Repairs}

Minor damage is occasionally repaired solely by filling it with soft material forced or molded into the gap (Strachan 2010b:64-65). Mud or clay, tar, moss, seaweed, and other soft vegetable matter were used as fillers in the British and Irish boats, and the use of animal fat and beeswax has been recorded ethnographically (Goodburn 2002:110). Soft fillers can also be used as caulking to supplement a repair by any of the other methods.

\section{Replacement of Damaged Fittings}

It is rarely possible to establish whether fitted components are original or replacements. Although the replacement of components was probably common, only one example has been convincingly identified: The full-size transom of the Carpow logboat appears to be a replacement associated with other repairs made to the boat's stern (Strachan 2010b:77-80). This identification was made partly on the basis of the transom's fresh tool marks, which contrast markedly with the more worn surfaces on the rest of the boat. The replacement 


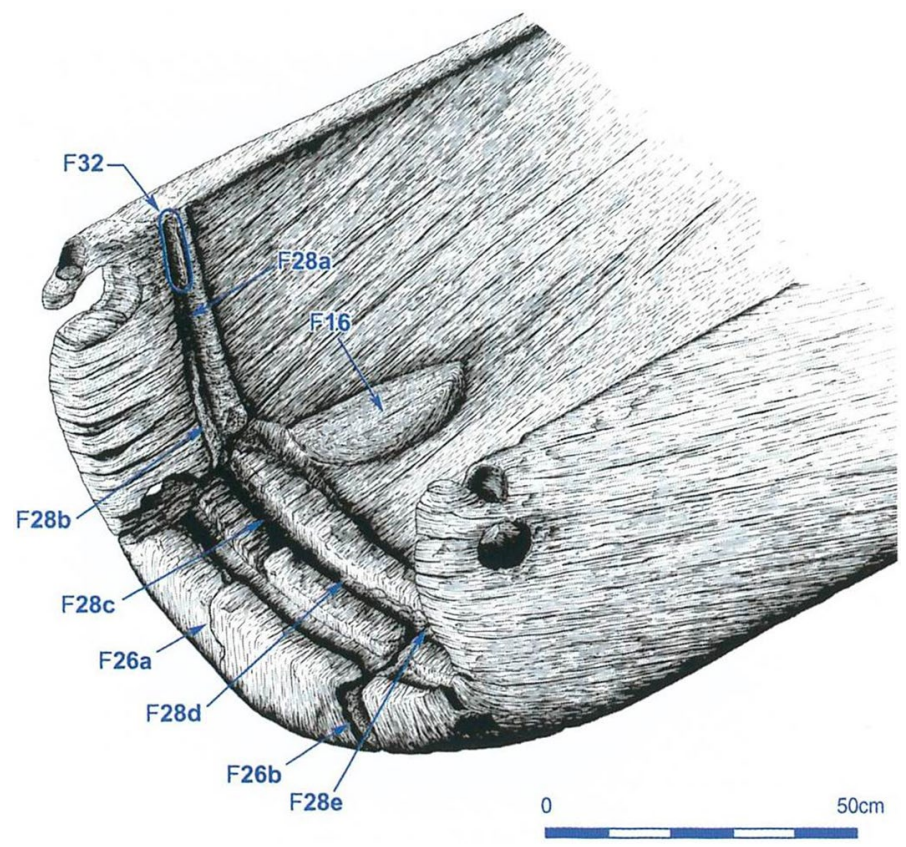

Fig. 7 Stern of the Carpow logboat. The slot for miniature repair transom is aft of the taller slot for the main transom (indicated by depth locations F28b-d and F32). The hole for the port peg that secured the top of the miniature transom is easily visible just to the right of the label F28b; the hole for the starboard peg is just barely visible near the bottom of the image. (Strachan 2010b:71/fig.100; used by permission)

was probably necessitated by spreading of the hull due to the expansion of a split propagating from the stern, so that the original transom was no longer wide enough to enclose the back end of the boat. Other "replacement" repairs may be necessitated by damage to the fitted component itself, although no such examples are known.

\section{A Nonconforming Repair}

One repair in the dataset is not easily accommodated by any of the previous categories and resists inclusion in the proposed typology. The Carpow logboat shows evidence of a miniature transom fitted outboard of the full-size transom. Although the miniature transom timber was not recovered, its form is apparent from a groove in the inside bottom of the hull, flanked by holes bored through the hull at the top of the groove on either side (Strachan 2010b:80-81) (Fig. 7). It is neither a patch nor a flush repair. In design, it appears most like a cleat or frame in a pulling repair, except that the fastening holes in the hull are in-line with any spreading force across the crack which it was apparently intended to repair. As such, pegs driven through the holes and into the opposite sides of the miniature transom board would not make the repair very secure against further spreading. In all other instances of pulling repairs, fasteners are driven into the hull perpendicular to the spreading force, to resist pull-out. The board was apparently so short (from bottom to top) that it would have been under water when the boat was afloat, so it could not have served by itself as a true transom to enclose the back end of the boat, but might have served as an extension 
of the full-size transom if the space between was caulked with some soft material such as clay (Strachan, David: pers comm, 08/12/20).

Strachan's interpretation of the miniature transom is that it was a repair "probably responding to leaking through basal splits and designed to restrain differential vertical movement of the two sides of the split rather than lateral separation" (Strachan 2010b:80-81, internal cross-reference omitted). This is unconvincing. While the fastening holes are bored into the hull in the proper direction to resist "differential vertical movement of the two sides of the split," it seems unlikely that such movement would have constituted a problem in need of a separate repair. The full-size transom, only a few centimeters forward of the miniature one, was secured by wedges, a beam tie, and possibly by a crossplank or seat as well; in combination, these would have done much to resist differential vertical movement of the two sides. Furthermore, the fastener holes were bored into the hull only at the upper ends of the timber, which is rather far from the split. A more effective approach to restrict differential vertical displacement would have been a cleat fastened into the end grain of the bottom across the split.

Although Carpow's construction was probably managed by a boatbuilding specialist (Strachan 2010a:171), it is possible that a less knowledgeable individual performed the repairs (Strachan, David: pers comm, 05/01/21), which could explain the apparent shortcomings in the technical approach represented by the miniature transom, and thus support Strachan's interpretation of its intended function. That the miniature transom was a repair is clear, but as its function is not fully understood, it cannot yet be fitted comfortably into the proposed typology. In terms of design, it most closely resembles a cleat or frame fastened with pegs, and as it is evidently a split repair (albeit a poorly understood one), it might provisionally be categorized as a pulling repair.

\section{Typology of Damage}

A typology of damage may be a necessary adjunct to a typology of repair. The damage described in the data sources can be sorted into four categories:

Splits and cracks. These are openings in the hull along the grain of the wood, usually propagating from one end of the log, but occasionally where the grain of the wood runs out along the boat's sheerline on one side or the other. While most splits are caused by uneven drying of the wood, a star shake is a split caused by internal stresses that build up while the tree grows. Although splits occur naturally and cracks are caused by mechanical impact, the terms are often used interchangeably and it is not always possible to distinguish between them. Splits and cracks are the most common type of damage in the data, accounting for about half of all instances.

Fractures: Where wood has been broken across the grain but remains attached at one end at least.

Missing wood. A section of wood may be absent due to rot, insect damage, mechanical damage, fire, knotholes (where a knot that has fallen out), accidental removal during construction or repair, or intentional excision of damage from other causes.

Loose knots. Where a knot shrinks but does not fall out, remaining loosely fixed in the hole and allowing water to pass through. 
25

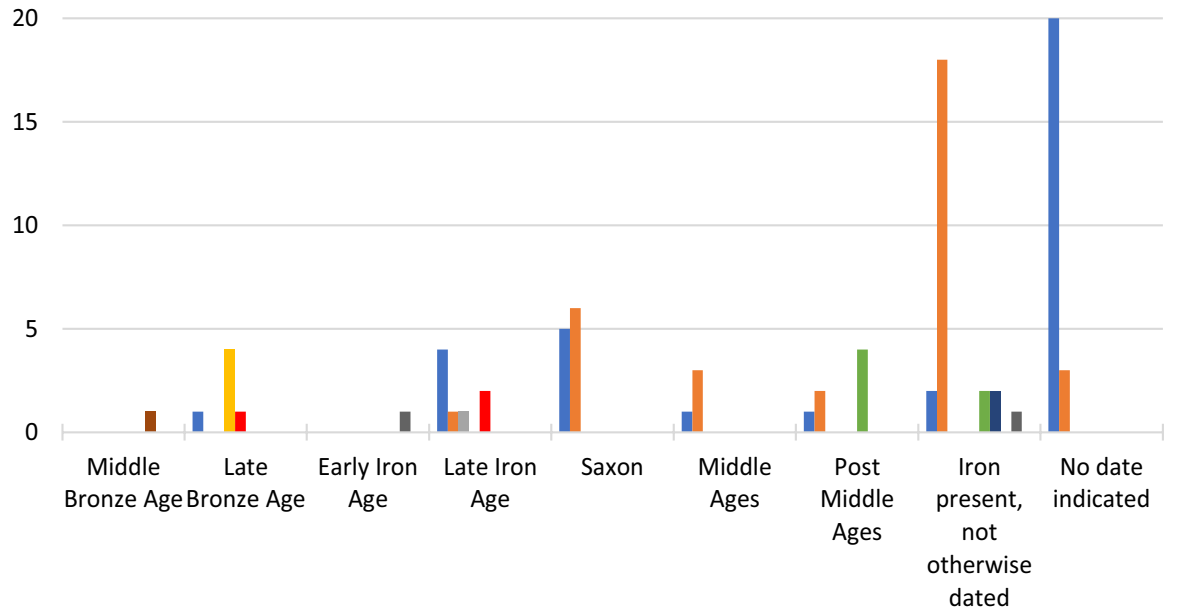

peg $\square$ nail $\square$ wedge $\square$ stitched $\square$ tenon $\square$ peg\&nail $\square$ staple $\square$ multiple/other $\square$ present $\square$ other

Fig. 8 Fastener use by era: number of repairs (Color figure online)

\section{Distributions}

Various distributions of the data in the spatial, temporal, and technological realms were examined. The small number of repaired boats in the dataset $(n=73$, of which 29 are reliably dated), the serendipitous nature of most logboat finds, and the large number of basic repair methods identified $(n=12)$ prevent drawing many meaningful conclusions from the results in terms of spatial or temporal distribution of repair methods across Britain and Ireland between the Middle Bronze Age and the post-medieval period.

Repairs were geographically widespread and occurred in every almost area where logboats have been found in significant concentrations throughout the Atlantic Archipelago. (Compare Fig. 5 to Gregory 1997:144/fig.10.3 for Ireland, Gregory 1997:145/fig.10.4 for Scotland, and McGrail 1978: v2/fig.207 for England and Wales.) This suggests that the practice of repair was universal among logboat users and not restricted to specific cultural groups.

The use of fasteners changed over time (Fig. 8), although the data are not robust. Stitching was the most common fastening method used during the Bronze Age but disappears thereafter. Treenails are the most common fastener in the Late Iron Age and are roughly equal with iron nails during the Anglo Saxon period, after which iron nails become the most common fastener. This shift is probably associated with the development of related technologies. Bronze Age boatbuilders did not have access to augers, and bronze gouges were the most efficient tool for cutting stitch holes (Goodburn 2004:133). Augers, which became available during the Iron Age, allowed boatbuilders to easily bore round holes for the first time, making treenails an efficient and much more durable method of fastening. When iron production expanded during the Anglo Saxon period and later, nails became a quick and economical method for making patch and cleat repairs. 


\section{Conclusions}

It is human nature to sort information into categories as an aid to cognition and to otherwise simplify analysis. The proposed typology can be used to consider any logboat repair in terms of similarities to and differences from others. For example, it highlights the unique nature of the Carpow logboat's miniature transom and suggests a need for further analysis of this confusing repair feature.

Based on "engineering" approaches, the proposed typology is a modern, etic conception. Whether it coincides with emic conceptions of repairs is unknowable. Those who repaired logboats in the past might have categorized their options differently (by material, for example, or by the nature of the damage) or might not have considered categories at all (see Read 2007:12-44; also Hurcombe 2007:58). Ethnographic studies among current logboat users might shed light on this. Although other parts of the world were not surveyed, this typology for Britain and Ireland might prove useful as a starting point for analysis of logboat repairs in any region. Methods other than those found in Britain and Ireland might be identified elsewhere, requiring the creation of new categories or realignment of the ones proposed here.

Supplementary Information The online version contains supplementary material available at https://doi. org/10.1007/s11457-021-09292-2.

Funding Not applicable.

Data Availability Provided as supplemental material for online publication.

\section{Compliance with Ethical Standards}

Conflict of interest Author declares that he has no conflict of interest.

Open Access This article is licensed under a Creative Commons Attribution 4.0 International License, which permits use, sharing, adaptation, distribution and reproduction in any medium or format, as long as you give appropriate credit to the original author(s) and the source, provide a link to the Creative Commons licence, and indicate if changes were made. The images or other third party material in this article are included in the article's Creative Commons licence, unless indicated otherwise in a credit line to the material. If material is not included in the article's Creative Commons licence and your intended use is not permitted by statutory regulation or exceeds the permitted use, you will need to obtain permission directly from the copyright holder. To view a copy of this licence, visit http://creativecommons.org/licenses/by/4.0/.

\section{References}

Adams J (2013) A maritime archaeology of ships: innovation and social change in late medieval and early modern Europe. Oxbow Books, Oxford

Andersen S (1994) New finds of Mesolithic logboats in Denmark. In: Westerdahl C (ed) Crossroads in ancient shipbuilding. Proceedings of the Sixth International Symposium on Boat and Ship Archaeology, Roskilde 1991. Oxbow Monographs, Oxford, vol 40, pp 1-10

Arnold B (2000) 'Monoxyles d'Europe-2000' (database on DVD). Beat Arnold

Arnold B (2018) Typologie et influence des bases monoxyles dans la construction navale traditionnelle, à l'image des esquifs réalisés par encorbellement inverse. Archaeonautica 20:165-182

Balakrishnan N, Dharmaraj K (1983) Marine wood boring molluscs of the Lakshadweep Archipelago. Indian J Mar Sci 12:96-99 
Blue L, Whitewright J, Cooper JP (2017) The ubiquitous hūrī: maritime ethnography, archaeology and history in the western Indian Ocean. In: Gawronsky J, Van Holk A, Schokkenbroek J (eds) Ships and maritime landscapes: Proceedings of the Thirteenth International Symposium on Boat and Ship Archaeology, Amsterdam 2012. Barkuis Publishing, Eelde, pp 185-191

Boulton EHB, Jay BA (1944) British timbers: their properties, uses and identification. Adam and Charles Black, London

Brady K (2014) Secrets of the lake: the lough Corrib Logboats. Archaeol Irel 28(4):34-38

Budka J (2010) The use of pottery in funerary contexts during the Libyan and Late Period : a view from Thebes and Abydos. In: Bareš L, Coppens F, Smoláriková K (eds) Egypt in transition. Social and Religious Development of Egypt in the First Millenium BCE. Czech Institute of Egyptology, Prague, pp $22-72$

Caple C (2006) Objects: reluctant witnesses to the past. Routledge, Abingdon

Cherry J, Cherry J (1984) Dugout boat from Wasdale Beck, Cumbria, 1984. CWAAS Trans 5:103-114

Christensen C (1990) Stone Age dug-out boats in Denmark: occurence, age, form and reconstruction. In: Robinson DE (ed) Experimentation and reconstruction in environmental archaeology: Symposia of the Association for Environmental Archaeology No. 9, Roskilde, Denmark, 1988. Oxbow Books, Oxford, pp 119-142

Creasman PP (2010) A further investigation of the Cairo Dahshur Boats. J Egypt Archaeol 96:101-123

Crumlin-Pedersen O, Jensen H (2018) Viking and Iron Age expanded boats. The Viking Ship Museum of Roskilde, Roskilde

Darrah R (2004) The reconstruction experiment. In: Clark P (ed) The Dover Bronze Age Boat. English Heritage, Swindon, pp 164-188

David N, Kramer C (2001) Ethnoarchaeology in action. Cambridge University Press, Cambridge

Davidson RW, Lombard FF, Hirt RR (1947) Fungi causing decay in wooden boats. Mycologia 39(3):313-327

Dudley HE (1943) The One-tree Boat at Appleby, Lincolnshire. Antiquity 17(67):156-161

Edberg R (2013) Subterranean maritime archaeology in Sigtuna, Sweden: excavated evidence of Viking Age boat building and repair. Int J Naut Archaeol 42(1):196-204

Fenwick V (2015) A cognitive approach to extant boat structure in Goa, India. Int J Naut Archaeol 44(2):388-409

Fry M (2000) Coití: Logboats from Northern Ireland. Greystone Press, Antrim

Fuquen Gomez C (2014) Logboats of Coquí: an ethnographic approach to maritime material culture. Ph.D. thesis, Department of Archaeology, University of Southampton

Gilmore MP, Eshbaugh WH, Greenberg AM (2002) The use, construction, and importance of canoes among the Maijuna of the Peruvian Amazon. Econ Bot 56(1):10-26

Goodburn D (2002) An archaeology of early English boatbuilding practice c.900-1600 AD. Ph.D. thesis, Department of Medieval Archaeology, University College London

Goodburn D (2004) Assembly and construction techniques. In: Clark P (ed) The Dover Bronze Age Boat. English Heritage, Swindon, pp 124-162

Goodburn D (2010) Reconstructing manufacture: tools, techniques and logistics. In: Strachan D (ed) Carpow in context: a late Bronze Age logboat from the Tay. Society of Antiquaries of Scotland, Edinburgh, pp 95-113

Goodburn D (2019) Evidence for the building of the Poole logboat. In: Berry J, Parham D, Appleby C (eds) The Poole Iron Age Logboat. Archaeopress, Oxford, pp 11-34

Goodburn D, Redknap M (1988) Replicas and wrecks from the Thames area. Lond Archaeol 6(11): 7-10, 19-22

Gould RA (1980) Living archaeology. Cambridge University Press, Cambridge

Graham S, Thrift N (2007) Out of order: understanding repair and maintenance. Theory Cult Soc 24(3): $1-25$

Gregory N (1997) A comparative study of Irish and Scottish Logboats. University of Edinburgh, Edinburgh

Gregson N, Metcalfe A, Crewe L (2009) Practices of object maintenance and repair: how consumers attend to consumer objects within the home. J Consum Cult 9(2):248-272

Highley TL (1999) Biodeterioration of wood. In: Wood handbook: wood as an engineered material. US Dept. of Agriculture, Forest Service, Forest Products Laboratory Gen. Technical Report FPLGTW-113, pp. 13/1-13/16

Holtzman R (2019) Logboat repairs in the British Isles: methods, distribution, and decision-making. Unpublished Masters dissertation, Department of Archaeology, University of Southampton

Houston L (2017) The timeliness of repair. Continent 6(1):51-55

Hsieh J (2016) The practice of repairing vessels in ancient Egypt: methods of repair and anthropological implications. Near East Archaeol 79(4):280-283 
Hurcombe LM (2007) Archaeological artefacts as material culture. Routledge, Abingdon

Jervis B, Kyle A (2012) Introduction. In: Jervis B, Kyle A (eds) Make-do and Mend: archaeologies of compromise, repair and reuse (BAR International Series 2408). Archaeopress Publishing Ltd, Oxford, pp 3-4

Kyle A (2012) More than just a quick fix? Repair holes on early Medieval Souterrain Ware. In: Jervis B, Kyle A (eds) Make-do and Mend: archaeologies of compromise, repair and reuse (BAR International Series 2408). Archaeopress Publishing Ltd, Oxford, pp 81-95

Lanting JN (1997) Dates for origin and diffusion of the European Logboat. Palaeohistoria 39(40):627-650

Malinowski B (1922) Argonauts of the Western Pacific. Routledge \& Kegan Paul Ltd, London

Markoulaki P (2015) Depositional practices in the wetlands: the case of prehistoric Logboats in England. Ph.D. thesis, Department of Archaeology, University of Nottingham

Marsden P (2004) Description of the boat. In: Clark P (ed) The Dover Bronze Age Boat. English Heritage, Swindon, pp 32-95

Marsden P et al (1989) A late Saxon logboat from Clapton, London Borough of Hackney. Int J Naut Archaeol 18(2):89-111

McGrail S (1978) Logboats of England and Wales with comparative material from European and other countries. Greenwich: BAR British Series 51(i), National Maritime Museum

McGrail S (1998) Ancient Boats in North-West Europe: the archaeology of water transport to AD 1500. Addison Wesley Longman, Harlow

McGrail S (2001) Boats of the World: from the Stone Age to Medieval times. Oxford University Press, Oxford

Millett M et al (1987) The Archaeology of the Hasholme Logboat. Archaeol J 144(1):69-155

Mowat RJC (1996) The Logboats of Scotland. Oxbow Books, Oxford

Ransley J (2009) The backwater boats of Kerala: identity, place and the World of Munruthuruthu. Ph.D. thesis, Department of Archaeology, University of Southampton

Read DW (2007) Artifact classification: a conceptual and methodological approach. Left Coast Press, Walnut Creek

Robinson I, Knight M, Murrell K (2012) Must Farm Palaeochannel Investigations 2009-2012: Post-excavation Assessment. Cambridge

Strachan D (2010a) Conclusions: the Carpow logboat in context. In: Strachan D (ed) Carpow in Context: A late Bronze Age logboat from the Tay. Society of Antiquaries of Scotland, Edinburgh, pp 163-179

Strachan D (2010b) A description of the boat. In: Strachan D (ed) Carpow in Context: A late Bronze Age logboat from the Tay. Society of Antiquaries of Scotland, Edinburgh, pp 57-89

Tanner P (2019) The Poole logboat: digital comparisons. In: Berry J, Parham D, Appleby C (eds) The Poole Iron Age Logboat. Archaeopress, Oxford, pp 35-86

van Rensburg JJ (2010) The Hawārī of Socotra, Yemen. Int J Naut Archaeol 39(1):99-109

Wheeler C (2012) Beyond a "Make-do and Mend" Mentality: Repair and reuse of objects from two medieval village sites in Buckinghamshire. In: Jervis B, Kyle A (eds) Make-do and Mend: archaeologies of compromise, repair and reuse (BAR International Series 2408). Archaeopress Publishing Ltd, Oxford, pp 97-106

Willmott H (2001) A group of 17th-century glass goblets with restored stems: considering the archaeology of repair. Post-Medieval Archaeol 35(1):96-105

Wylie A (1985) The reaction against analogy. Adv Archaeol Method Theory 8:63-111

Yde, J. (1965) Material culture of the Waiwái. Copenhagen: Nationalmuseets Skrifter (Etnografisk Rœkke, 10)

Publisher's Note Springer Nature remains neutral with regard to jurisdictional claims in published maps and institutional affiliations. 